\title{
A Study of the Security System for the Current Hearing Aid Fitting and Application Programs
}

\author{
Dokyun Kim, Taehwa Kim', Jinsook Kim², \\ 'Department of Speech Pathology and Audiology, Graduate School, Hallym University, Chuncheon, Korea \\ ${ }^{2}$ Division of Speech Pathology and Audiology, Research Institute of Audiology and Speech Pathology, \\ College of Natural Sciences, Hallym University, Chuncheon, Korea
}

최신 보청기 적합 및 어플리케이션 프로그램의 보안 실태 연구

김도균 ${ }^{1}$ 김태화 ${ }^{1} \cdot$ 김진숙 ${ }^{1,2}$

한림대학교 일반대학원 언어병리청각학과', 한림대학교 자연과학대학 언어청각학부 · 청각언어연구소 ${ }^{2}$

\begin{abstract}
This review aims to identify the current status of the hearing aid fitting program and applications for six major manufacturers in terms of security system and to suggest supplementary methods and solutions for strengthening security. First of all, we analyzed the hearing aid fitting programs and applications for the six manufacturers. When the hearing aid fitting programs were executed, we examined authentication processes, encryption systems, and individual data logging operations. To identify whether a third party could access and operate the hearing aid through the application, authentication processes and technologies used for connection between the hearing aid and the application were also examined. Among the six hearing aid fitting programs, two manufacturers' systems had authentication processes, one had access control program installed in the customer database, and the individual data logging could turn on/off in five hearing aid fitting programs. All manufacturers had no authentication processes in the hearing aid applications. Bluetooth was used for connection technology for all manufacturers, and the acoustic signal was used in two manufacturers' programs. In most cases, the third parties were able to control the hearing aid using the vulnerability of Bluetooth and the acoustic signal. It is necessary to improve the security system by applying users authentication process, customer data encryption, role-based access control, audit trail, and automatic update function to the hearing aid fitting program. The security system of hearing aid application connected to Bluetooth and/or acoustic signal should be improved by adding a function of the user authentication and identification process of particular hearing aid for application usage.
\end{abstract}

Key Words: Security system, Personal information, Authentication, Access control, Encryption.

Received: May 20, 2019 / Revised: July 10, 2019 / Accepted: July 16, 2019

Correspondence: Jinsook Kim, Division of Speech Pathology and Audiology, Research Institute of Audiology and Speech Pathology, College of Natural Sciences, Hallym University, 1 Hallymdaehak-gil, Chuncheon 24252, Korea

Tel: +82-33-248-2213 / Fax: +82-33-256-3240 / E-mail: jskim@hallym.ac.kr

\section{INTRODUCTION}

청각장애는 우리나라 15 개 장애 분류 중 지체장애에 이어 제 2위에 해당하는 발생률이 높은 감각장애 중 하나이다(Ministry of Health and Welfare, 2018). 난청이 발생하면 가족, 친구, 직 장 동료들과 대화가 힘들어지고 주위 환경음을 듣지 못하게 되

(c) This is an Open Access article distributed under the terms of the Creative Commons Attribution Non-Commercial License (https://creativecommons.org/licenses/by-nc/4.0) which permits unrestricted non-commercial use, distribution, and reproduction in any medium, provided the original work is properly cited.
어 안전에 위협이 될 수도 있다. 이러한 문제를 극복하기 위해 보청기를 착용하거나 인공와우 수술을 하게 되는데 더 널리 사 용되는 것이 보청기이다. 최근에는 보청기 기술의 발전과 스마 트 보조기술의 도입으로 주요 보청기 제조사에서는 보청기를 원격 제어할 수 있는 전용 어플리케이션(이하 앱)을 제작하여 스마트폰이나 태블릿 같은 모바일 장치로 다운로드 할 수 있게 하고 있다. 적절한 앱을 실행할 수 있는 스마트폰은 의사소통 문제에 다각적 도움을 줄 수 있어 청각장애인의 경우 노년층을 포함하여 빠른 사용 증가율을 보이고 있다. 이러한 앱은 특정 
목적을 충족시키도록 고안된 프로그램으로 다양한 분야에서 편리하게 사용되는데 보청기 착용자에게도 사용의 편리를 제 공해 준다(Doughty, 2016).

보청기 착용자는 앱을 실행하여 보청기와 다른 보조 장치를 무선으로 연결한 후 스마트폰, 텔레비전, MP3 플레이어에서 나 오는 소리를 무선으로 보청기에 전달하여 들을 수 있을 뿐만 아니라 필요에 따라 보청기의 마이크로폰 기능을 끄고 켜 듣고 자 하는 스트리밍 소리를 들을 수 있도록 주변 소음을 제거하 기도 하고 다양한 환경음을 분석한 자료를 근거로 최적의 소리 를 들을 수 있는 기술의 조합도 선택 가능하다. 더욱이 특정 환 경에서 무선으로 직접 전달되는 소리를 그 환경에 최적화된 신 호대잡음비를 선택하여 어떠한 소음이 존재하는 상황에서도 소음의 방해를 받지 않고 듣고 싶은 말이나 음악 소리를 잘 듣 도록 할 수도 있다(Doldouras, 2017).

스마트폰의 사용으로 보청기 착용자는 사물인터넷(Internet of Things) 서비스도 이용할 수 있다. 사물인터넷은 인터넷을 기반으로 모든 사물을 연결하여 사람과 사물 또는 사물과 사 물 간의 정보를 상호 소통하게 하는 지능형 기술과 관련된 서 비스를 말한다(ISO/IEC JTC 1, 2015). 인터넷으로 연결된 사 물인터넷은 보청기를 통해 사용자의 위치, 움직임, 심장 박동 수와 같은 다른 센서 데이터와도 연결할 수 있어 하루 동안 변 화하는 사용자 주변의 모든 음향 환경에 대한 다양한 데이터를 수집할 수 있다. 수집된 데이터를 통해 사용자의 보청기 볼륨과 프로그램 조절 방법, 소음에 대한 민감도, 그에 따른 인지 상태 에 대해 보청기의 특정 기능과 사용자의 상호 작용 등을 추적할 수 있고, 이렇게 입력된 데이터를 기반으로 상당한 양의 정보를 저장하고 그 데이터를 클라우드를 통해 제공받을 수도 있다. 이 러한 추적 방법은 기존의 한 가지 프로그램만 사용하는 보청기 적합 패러다임에서 음향 환경에 따라 행동 패턴의 신호를 적합 솔루션에 적용하여 여러 개의 프로그램을 동시에 적용할 수 있 는 고급화된 맞춤형 적합 프로그램으로 전환할 수 있게 한다. 따라서 사물인터넷을 적용한 보청기를 사용하면 자체 추적 시 스템을 기반으로 하는 멀티 적합 솔루션을 적용할 수 있어 청각 장애가 있는 사용자의 만족도를 높이고 삶의 질도 향상시킬 수 있다고 연구자들은 보고하였다(Johansen et al., 2018).

그러나 이렇게 유용한 사물인터넷 환경은 인터넷의 보안과 사물을 연결하는 보안 문제에 모두 노출되어 해커에 의한 개인 정보 유출 등의 취약점이 있다(Roshan \& Ray, 2016). 개인정보 란 개인에 관한 정보 즉, 성명이나 주민등록번호 혹은 영상 등 을 통하여 개인을 식별할 수 있는 정보를 말하는데, 해당 정보만 으로는 특정 개인을 알아볼 수 없더라도 다른 정보와 결합하여 쉽게 개인을 인식할 수 있는 포괄적인 의미도 포함한다(Ministry of Government Legislation, 2017). 개인정보의 유출은 보이스
피싱과 스미싱 등의 범죄에 악용되기도 하여 심각한 문제를 발 생시킬 수도 있는데(Chaudhry et al., 2016), 국내 금융감독원 보도자료에 의하면 2017년 보이스피싱 피해 건수는 49,948건으 로 전년 대비 $8.8 \%$ 증가하였고 그 피해액은 2,423억 원으로 전 년 대비 $26 \%$ 증가하였다. 대출 빙자형 보이스피싱은 40 대 이상 의 피해자 수가 $73.4 \%$ 로 높은 비율을 차지하였고 정부기관 사 칭형 등의 보이스피싱은 20 30대 여성이 50.6\%를 차지하여 보 이스피싱 범죄는 특정 성별이나 연령대에 따라 취약한 유형이 있는 것으로 나타났다(Choi, 2018).

2017년 한 해 동안 전 세계에서 발생한 데이터 유출량을 조 사한 보고서에 따르면 개인정보 유출 데이터 수는 약 26억 개 로, 매 초당 82 개의 개인정보 데이터가 유출되고 있는 매우 심 각한 상황인 것으로 조사되었다. 산업별 데이터 유출 사건을 분야별로 구분하여 살펴보면, 의료 분야가 $27 \%$ 로 가장 많았고 금융 분야가 $11 \%$, 교육 분야가 $11 \%$ 등의 순으로 나타났다 (Gemalto, 2017). 의료 분야에 대한 데이터 유출로 개인의 보안 침해의 가능성을 연구한 대표적 예로 아기의 행동을 감시하는 Video Baby Monitors의 해킹 연구가 있다. 6개 제조사의 7개 모델 Video Baby Monitors를 조사한 결과, 일련번호가 노출될 가능성이 높고, 인증과정 없이 카메라에 계정 생성이 가능하 며, 관리자 권한으로 사용이 가능한 점 등에서 보안의 취약점 이 발견되었다. 이런 취약점을 가진 모니터를 공격 대상으로 할 경우, $\mathrm{Wi}-\mathrm{Fi}$ 나 인터넷과 내외부 통신의 인터페이스로 침투하여 운영체제에 접근이 가능하므로 카메라 화면을 녹화하거나 조작 할 수도 있어 사생활 유출이나 데이터 손상에 대한 가능성이 존재하는 것으로 보고되었다(Stanislav \& Beardsley, 2015). 또 다른 의료 분야 데이터 유출의 문제성은 인간의 몸에 이식되는 심장박동기에서도 나타난다. 이를 연구한 보고서에서 공격자가 프로그램, 가정 모니터링 장치, 네트워크로 상호 연결되는 구조 에 침투하여 개인정보를 유출할 수 있고 심장박동기를 마음대 로 제어할 수도 있다고 경고하였다(Rios \& Butts, 2017).

이러한 개인정보의 침해와 유출로부터 안전한 환경을 조성하 기 위해서는 보안 시스템이 매우 중요하다. 특히 보안 시스템의 강화를 위해서 해당 기기와 자원에 대한 모든 접근을 제어하고 권한 있는 경우만 접근할 수 있도록 하는 접근제어 방법이 기 본적으로 제공되어야 한다. 접근제어는 로그인 프로세스에서 사용자가 인증을 하고 데이터를 추가, 삭제, 수정할 수 있는 사 용자 역할의 권한 부여를 포함한다. 더욱이 데이터베이스 관리 시스템은 기본 운영체제가 제공하는 접근제어 방법 외에 자체적 으로 접근제어를 적용하여 보안을 더욱 강화할 수도 있다(De Capitani di Vimercati et al., 2002).

현대 과학기술의 발달은 편리성을 제공하는 반면 스마트폰 의 사용 장소, 인터넷 접속 기록, 데이터 소비량 등의 정보도 상 
황에 따라 개인정보로 활용이 가능하여 개인정보의 노출 위험 이 더 심각하다. 사물인터넷 시대로 이제 막 진입한 보청기도 착용자의 사용 환경, 사용 시간, 착용 방향 등과 같은 데이터가 개인정보로도 활용될 수 있어서 편리성과 개인정보 노출 위험 의 심각성을 동시에 안고 있다. 따라서 보청기 착용자의 개인정 보 보안을 위해 적절한 보안 대책이 보청기나 관련된 프로그램 에 잘 적용되고 있는지 살펴볼 필요성이 있다. 특히 보청기와 무선으로 연결되는 앱의 발달로 앱과 연관된 보청기 프로그램 도 개인정보 노출에 취약할 수 있으므로 본 연구는 보청기 제 조사들의 적합 프로그램과 앱의 보안에 관한 현재의 보안 시스 템의 상황을 분석하고 보안과 관련하여 어떠한 기술들이 있는 지 확인하고 앞으로 문제가 될 수 있는 개인정보와 데이터 유출 의 해결 방법을 제안하고자 한다.

\section{THE SECURITY SYSTEM OF THE HEARING AID FITTING AND APP PROGRAMS}

\section{조사 대상 및 방법}

6개의 주요 보청기 제조사 벨톤, 오티콘, 포낙, 지멘스, 스타 키, 와이덱스의 보청기 적합 프로그램과 앱을 대상으로 보안에 관련된 사항을 중심으로 분석하였다. 6 개 보청기 제조사를 임 의로 $\mathrm{A}, \mathrm{B}, \mathrm{C}, \mathrm{D}, \mathrm{E}, \mathrm{F}$ 로 표기하였다. 첫 번째, 보청기 적합 프 로그램의 보안 실태를 분석하기 위해서 보청기 적합 프로그램 을 실행하였을 때 사용자 인증과정이 존재하는지, 고객 데이터 에 암호화가 적용되는지, 데이터 로깅이 개인별로 on/off가 가 능한지에 관련된 사항을 조사하였다. 두 번째, 앱 소프트웨어의 보안 실태를 분석하기 위해 앱을 실행하였을 때 사용자 인증과 정이 존재하는지, 보청기와 앱의 연결은 어떤 기술을 사용하는 지, 제 3 자가 앱을 통해 보청기를 조작할 수 있는지에 관련된 사 항을 조사하였다.

\section{보청기 적합 프로그램의 보안 실태 분석}

인증(Authentication)과정

보청기 적합 프로그램에서 인증과정이 존재하는 제조사는
2군데였다. 인증과정이 존재하는 2 개 제조사는 $\mathrm{ID} /$ password를 직접 입력해야 하거나 ID/password를 직접 입력할 수도 있고 자동 로그인도 가능한 제조사로 나뉘었다. 2 개 제조사 모두 인 증과정에서 $\mathrm{ID} / \mathrm{password}$ 는 각각 3 자리이고 하드코드화 되어 있어서 제 3 자가 임의로 변경할 수 없도록 되어 있었고, 이 중 1 개 제조사는 ID/password를 변경할 수 있는 프로그램도 별도 로 존재하여 인증과정의 보안 시스템이 강하였다(Table 1).

\section{고객 데이터의 암호화(Encryption)}

보청기 적합 프로그램에서 고객 데이터 파일이 쉽게 제 3 자에 게 노출되지 않기 위해 고객 데이터베이스에 접근제어 프로그 램이 설치된 제조사는 1 군데였다. 또한 암호화가 보청기 적합 프로그램에 설정되어 고객 데이터 파일이 안전한지 확인하기 위하여 고객 데이터 파일을 복사하여 다른 컴퓨터의 같은 폴더 에 붙여넣기 하였을 때 복사된 고객 데이터를 볼 수 있는 제조 사는 3군데였다(Table 1).

데이터 로깅(Data logging) on/off

보청기 적합 프로그램에서 보청기 착용자의 착용 시간, 착용 환경, 프로그램 변경, 볼륨 변경과 같은 사용 기록을 데이터 로 깅이라고 한다. 이러한 데이터 로깅 기능을 개인별로 on/off 할 수 있는 제조사는 5 군데였고, 나머지 1 군데는 모든 고객에 일괄 적으로만 on/off 할 수 있었다(Table 1).

\section{앱 소프트웨어의 보안 실태 분석}

\section{인증과정}

보청기 앱을 실행할 때 ID와 password 같은 인증과정이 존 재하는지 조사한 결과 6 개 제조사 모두 인증과정이 존재하지 않는 것으로 확인되었다(Table 2).

보청기와 앱의 무선연결(Wireless control) 방식

보청기와 앱의 무선연결 방식은 현재 블루투스(bluetooth)와 음향신호(acoustic signal)를 이용하는데 블루투스 방식은 스마 트폰의 운영체제에 따라 별도의 게이트웨이 장치가 필요한 경 우도 있다. 음향신호 방식은 스마트폰에 앱만 설치하면 보청기

Table 1. Security conditions of hearing aid fitting program for six hearing aid manufacturers

\begin{tabular}{llllll}
\hline \multicolumn{1}{c}{ Functions } & \multicolumn{5}{c}{ Manufacturers } \\
\cline { 2 - 6 } & A & B & C & D & E \\
\hline Authentication & - & - & - & - & + \\
Encryption access control to client database & - & - & - & - & - \\
Encryption client data file copy/paste & + & - & - & + & + \\
Individual data logging on/off & + & + & + & - & + \\
\hline
\end{tabular}


Table 2. Security controls of application softwares for six hearing aid manufacturers

\begin{tabular}{|c|c|c|c|c|c|c|}
\hline \multirow{2}{*}{ Functions } & \multicolumn{6}{|c|}{ Manufacturers } \\
\hline & $\mathrm{A}$ & B & $\mathrm{C}$ & $\mathrm{D}$ & $\mathrm{E}$ & $\mathrm{F}$ \\
\hline Authentication & - & - & - & - & - & - \\
\hline $\begin{array}{l}\text { Wireless control between hearing } \\
\text { aid and app }\end{array}$ & Bluetooth & Bluetooth & Bluetooth & $\begin{array}{l}\text { Bluetooth/ } \\
\text { Acoustic signal }\end{array}$ & $\begin{array}{l}\text { Bluetooth/ } \\
\text { Acoustic signal }\end{array}$ & Bluetooth \\
\hline
\end{tabular}

의 소리를 제어할 수 있어서 사용하기에 더 편리하지만 블루투 스 방식처럼 스마트폰의 음악을 무선으로 들을 수 있는 기능은 제공하지 못한다. 6 개 보청기 제조사 모두 블루투스 방식을 사 용하였고 보청기 배터리 도어를 열었다가 닫는 과정을 통해 보 청기와 스마트폰을 페어링(pairing)하였다. 블루투스 방식은 페 어링 과정이 존재하기 때문에 타인의 보청기 도어를 열고 닫을 수만 있다면 스마트폰과 연결되어 임의로 제어할 수 있었다. 보 청기와 앱을 연결함에 있어서 음향신호 방식을 사용하는 제조 사는 2 군데였다(Table 2). 음향신호를 사용하는 2 개의 제조사 중 $\mathrm{D}$ 는 앱으로 보청기 볼륨을 조절할 때 스마트폰에서 생성되 는 음향신호를 거의 들을 수 없었던 반면 제조사 $\mathrm{E}$ 는 음향신호 가 들리는 구조였다. 2 개 제조사 모두 제 3 자가 앱을 실행하여 음향신호를 보청기로 입력시키기만 하면 보청기 착용자의 보청 기를 임의로 제어할 수 있는 것으로 확인하였다.

\section{RESULTS AND DISCUSSIONS}

본 연구 결과 보청기 제조사의 사용자 인증과정의 존재비율 은 보청기 적합 프로그램을 실행할 때 $33.3 \%$, 보청기 앱을 실 행할 때 $0 \%$, 고객 데이터베이스 프로그램을 실행할 때 $16.6 \%$ 로 보안에 취약한 구조인 것으로 나타났다. 이와 같이 인증되 지 않은 접근을 차단하기 위해서는 선행연구에서 제안한 대로 접근제어 시스템을 하루 빨리 적용시켜야 한다(De Capitani di Vimercati et al., 2002). 한편 고객 데이터베이스 프로그램에 접 근할 때 접근제어를 사용하는 업체의 로그인 ID/password가 보청기 적합 프로그램에 로그인할 때 사용하는 ID/password 와 똑같아서 고객 데이터베이스 프로그램과 보청기 적합 프로 그램의 사용자 식별자는 서로 독립적이지 않은 것으로 나타났 다. 더욱이 고객 데이터베이스 프로그램에 접근할 때 사용하는 $\mathrm{ID} /$ password는 모두 하드코드화 되어 있어서 수정할 수 없게 되어 있었다. 이는 사용자를 식별하는 ID가 관리자의 성격을 내포하는 형태로 어떠한 사용자도 동일한 ID로 접속하는 구조 이기 때문에 보청기 센터 내 내부자가 고객 데이터를 유출할 가 능성을 배제할 수 없다. 그러므로 고객 데이터베이스 프로그램 에 접근하는 $\mathrm{ID}$ 는 보청기 적합 프로그램에서 사용하는 ID와 는 독립적으로 설정할 수 있도록 프로그램이 개선되어야 한다.

데이터, 특히 고객 데이터는 최대한 비밀을 보장해야 할 필요
성이 있음에도 불구하고 고객 데이터 폴더의 파일을 복사하여 다른 컴퓨터의 같은 폴더에 붙여넣기 하여 보청기 적합 프로그 램을 실행하였을 때 복사한 고객 데이터를 볼 수 있는 제조사 의 비율은 $50 \%$ 였다. 개인용 컴퓨터, 스마트폰, USB 등과 같은 최종 사용자 장치(end user device)에 저장된 정보에 대한 접근 을 제한하기 위한 기본 보안 시스템은 앞서 제안한 인증과정의 개선과 함께 암호화가 필요하다. 저장소 보안(storage security) 은 허가된 사용자만 저장된 정보에 접근하고 사용할 수 있게 하는 프로세스로 저장소 암호화 소프트웨어를 통해 중요한 정 보를 보호할 수 있다. 저장소 암호화 소프트웨어는 자신이 저장 한 정보를 암호화할 수 있어서 민감한 정보를 포함하는 데이터 베이스를 구성할 수도 있다(Scarfone et al., 2007). 이와 같은 시스템을 적용한 제조사 $\mathrm{F}$ 는 유일하게 고객 데이터베이스에 접 근제어를 적용한 소프트웨어가 별도로 존재하였다. 나머지 제 조사들도 저장소 암호화 소프트웨어의 기능을 하는 응용 프로 그램을 개발하여 어떤 경로로 유출될지 모르는 고객 데이터를 보호해야 할 필요성이 있다. 그러므로 최종 사용자 장치에 저장 된 고객 데이터는 인증을 통해 안정성이 보장되고 암호화된 소 프트웨어를 통해서만 세부적인 내용을 확인할 수 있도록 설계 되어야 한다고 생각한다.

현재 6개 제조사 중 인증을 사용하지 않는 4개 제조사의 보 청기 적합 프로그램은 실행만 가능하면 고객의 개인정보를 모 두 열람할 수 있으며 인증을 사용하는 2개 제조사도 로그인하 여 프로그램을 실행하게 되면 고객의 개인정보를 살펴볼 수 있 게 되어 있다. 이는 보청기 적합 프로그램을 실행할 수 있는 사 람이라면 고객 데이터에 얼마든지 접근하고 또한 유출도 가능 하게 되어 있으므로 접근제어만으로는 보안의 취약성을 근본 적으로 해결할 수 없다. 따라서 보청기 센터의 직책에 따라 고 객 데이터의 읽기, 수정, 삭제, 백업 등이 제한되어야 하는 역할 기반 접근제어(role-based access control)의 적용이 필요하다. 역할기반 접근제어는 사용자에게 적절한 역할을 할당하여 접 근 권한을 역할에 따라 부여함으로써 데이터를 보호하는 방법 으로 역할은 의사 또는 약사와 같은 특정 작업을 수행하는 역 량을 나타내고 권한과 책임을 내포한다(Sandhu et al., 1996). Boadu \& Armah(2014)는 병원 의료 기록과 환자 정보에 대한 무단 접근으로부터 개인정보를 보호하기 위해 역할기반 접근제 어에 기반한 병원 관리 시스템을 제안하였다. 데이터는 정의되 
거나 권한이 부여된 사용자만 접근해야 된다는 원칙을 기본으 로 관리자 외에 역할을 접수원, 간호사, 의사로 정의하여 각각 의 역할에 따른 환자 개인정보 접근에 차별성을 두었다. 이와 같은 연구의 제안과 유사한 시스템이 보청기 적합 프로그램과 고객 데이터베이스 관리 시스템에도 필요한 것으로 생각된다. 예를 들어 보청기 센터의 경우 기본 세팅은 접수원, 청능사, 센 터장의 3 가지 역할로 구분하여 각각의 역할에 따라 고객 개인 정보를 읽기, 수정, 삽입, 삭제, 백업할 수 있는 범위를 제한할 수 있다. 보청기 착용자들은 대부분 고령자가 많아서 이름, 나 이만으로는 신분 확인이 힘든 경우가 상당수이므로 생년월일 로써 신분을 최종적으로 확인할 수 있다. 그러므로 보청기 센 터의 접수원은 고객 개인정보 중에서 이름, 생년월일만 읽기 가 능하도록 권한이 주어져야 할 것이다. 청능사는 접수원의 권한 과 보청기 적합 프로그램을 사용할 수 있는 권한을, 센터장은 청능사의 권한과 고객 데이터베이스에 직접 접근할 수 있는 권 한을 주어 역할기반 접근제어를 실현할 수 있을 것이다.

고객 데이터베이스를 허가된 사용자만 볼 수 있도록 하더라 도 허가된 사용자가 언제 접속해서 어떠한 액션을 취했는지에 관한 기록이 없으면 정보 유출의 가능성을 제공할 여지가 있다. 특히 병원의 의료 소프트웨어는 응급 상황이 발생하면 역할에 상관없이 누구나 고객 데이터에 접근 가능하도록 설계되어야 한 다. 이러한 종류의 비상 동작을 추적하려면 프로그램의 사용을 통해 발생하는 모든 사건들을 기록하는 감사추적(audit trail) 시 스템이 필요하다. 감사 내역은 “사용자 $\mathrm{x}$ 가 고객 $\mathrm{y}$ 의 기록을 보 았습니다"처럼 저장하므로 사용자가 자신의 작업이 기록되고 있다는 것을 알기 때문에 고객 데이터에 함부로 접근하지 못할 것이다(Armour \& Thizy, 2010). 따라서 언급한 대로 역할기반 접근제어에 기반하여 보청기 센터의 고객 데이터베이스에 접근 은 센터장에게만 권한을 부여하지만 청능사 직원이나 접수원 에게도 고객 데이터베이스에 접근이 가능하도록 권한을 부여 해야 할 경우엔 모든 작업 내역을 기록하는 고객 데이터 감사 추적을 적용하여 보안을 강화할 수 있는 기본 장치를 마련해야 한다. 더욱이 이렇게 기록된 내역은 고객 데이터베이스와는 다 른 별도의 데이터베이스에 저장하도록 하여 감사 내역을 볼 수 있는 특권이 있는 자만 접근할 수 있도록 한다면 고객 데이터 베이스에 접근하는 모든 사용자는 상위 관리자의 감사추적의 대상이 된다는 사실을 알게 됨으로써 구성원의 고객 개인정보 보호와 보안에 더욱 주의하게 되어 강화된 보안 시스템을 구축 할 수 있다.

보청기 적합 프로그램에서 데이터 로깅은 감사추적과 유사 하게 보청기 자체적으로 특정 사건을 기록하는 기능이다. 일반 적으로 로그(log)는 시스템과 네트워크에서 발생하는 사건에 관련된 정보의 기록이기 때문이다(Kent \& Souppaya, 2006).
보청기를 보청기 적합 프로그램에 연결하면 보청기 착용 시간, 착용 환경, 볼륨 변경 등과 같은 사용자의 개인정보를 데이터 로깅 메뉴에서 볼 수 있다. 이와 같은 개인정보를 수집하는 데 이터 로깅을 보청기 적합 프로그램에서 개인별로 on/off가 가 능한 제조사의 비율은 83.3\%였다. 특히 제조사 E는 2019년에 보청기 적합 프로그램 업그레이드를 통해 개인별로 데이터 로 깅 on/off를 가능하게 한 것으로 확인되었다. 이는 보청기 제조 사에서 데이터 로깅 기록을 중요한 개인정보로 취급하여 보안 을 위한 노력에 더욱 관심을 가지고 있다는 것을 의미한다. 개 인정보보호법 제 15 조 제1항 제1호에 의하면 개인정보 처리자는 정보 주체의 동의를 받은 경우 개인정보를 수집할 수 있으며 그 수집 목적의 범위에서 이용할 수 있다고 하였다(Ministry of Government Legislation, 2017). 이와 같은 이유로 보청기 적합 프로그램은 초기 피팅 시 데이터 로깅 off로 설정되어야 하며 청능사는 데이터 로깅의 on이나 off에 대한 결정 여부를 고객에 게 물어보고 동의를 얻은 경우에 on 하도록 해야 할 것이다. 이 러한 적합과정은 고객 차트에 수기로 적을 수도 있는데 고객 차 트는 인적 사항, 검사 결과, 보청기 보조금 관련 서류 등을 포함 하므로 고객 정보를 수기로 수집하는 경우에도 고객의 동의를 받거나 개인정보동의서를 받도록 개선될 필요가 있다. 개인정보 보호법 제 29 조에 의하면 개인정보 처리자는 개인정보가 분실· 도난·유출·위조·변조 또는 훼손되지 아니하도록 내부 관리계 획 수립, 접속 기록 보관 등 안전성 확보에 필요한 기술적·관리 적 및 물리적 조치를 하여야 한다고 하였다(Ministry of Government Legislation, 2017). 그러므로 보청기 제조사, 보청기 센 터 등 관련 업체에서는 개인정보보호법을 참고로 하여 고객 차 트에 관한 개별적인 보안 관련 준수사항을 마련해야겠다.

블루투스는 케이블이 필요 없는 무선통신으로 파일 공유가 쉽고 무선 동기화와 인터넷 연결이 가능한 장점으로 많은 사람 들이 사용하고 있지만 보안의 취약성으로 인해 개인정보 노출 의 위험성을 내재하고 있다. 일반적으로 블루투스는 개인적 영 역의 네트워크로 설계되었기 때문에 몇 발자국만 멀어지면 블 루투스에 접근할 수 없다고 알려져 있지만 해커가 높은 수신 강 도의 방향성 안테나를 사용하면 먼 거리에서도 공격이 가능하 다. 또한 블루투스 장치에서 사용되는 소프트웨어는 대체로 완 벽하지 않아서 취약하므로 사용하지 않을 때는 가급적 블루투 스를 꺼서 노출 위험을 방지해야 한다(Panse \& Panse, 2013). 그러나 해킹 공격을 방어하기 위해 블루투스를 꺼야 한다는 선 행연구의 제안은 보청기 착용자들에게는 적합하지 않은 방법 이다. 왜냐하면 스마트폰과 보청기를 블루투스로 연결해서 사 용하는 보청기 착용자들은 음악, 전화 벨소리 등을 잘 듣기 위 해 블루투스를 하루 종일 켜두어야 하는 경우가 대부분이기 때문이다. 따라서 보청기 착용자의 블루투스 연결은 해커의 표 
적이 될 것으로 예상되어, 블루투스를 항상 켜둔 상태에서도 보안을 유지할 수 있는 방안을 마련하는 연구를 통하여 블루 투스의 암호화 메커니즘 사용에 대한 개선이 필요하다. 본 연 구에서도 나타났듯이 보청기는 도어를 열었다가 닫는 페어링 과정을 거쳐 어떠한 스마트폰과도 연결이 가능하므로 보안 면 에서 더욱 취약한 결과를 보였다.

2010년 블루투스 4.0 버전에서 처음으로 소개된 블루투스 저전력(bluetooth low energy)은 동전 크기의 배터리를 사용하 는 메디컬 장치나 다른 센서를 위해 고안되었다. 블루투스 저전 력 페어링에서는 하나의 장치가 롱텀키(long-term key)를 생성 하고 키 전달 프로토콜(key transport protocol)을 사용하여 롱 텀키를 다른 장치로 전송한다. 블루투스 저전력 페어링 방법은 out of band, passkey entry, just works, numeric comparison 이 있는데 연결해야 할 두 개의 장치 중에 한 개의 장치가 키보 드 입력이나 디스플레이 출력이 불가능할 경우 just works 페어 링 방법이 사용된다. 블루투스 저전력 메커니즘에서 사용되는 just works 페어링 방법은 임시키(temporary key)가 모두 0으 로 정해지기 때문에 그 결과 인증되지 않은 롱텀키를 생성하므 로 도청자나 중간자 공격자가 임시키를 추측할 필요가 없고 페 어링 과정 동안 중간자 공격의 보호를 제공하지 않으므로 위 4 가지 페어링 방법 중에서 가장 취약한 방법이다. 보청기는 입 력, 출력이 불가능한 기계이므로 보청기 도어를 열었다가 닫는 과정을 통해 블루투스와 보청기를 페어링하는 것은 just works 방법이어서 더욱 취약하다고 볼 수 있다. 또한 보청기 앱 실행 시 사용자 인증과정이 존재하지 않을 경우 블루투스로 연결된 보청기 앱의 보안은 너무나 허술하다고 할 수 있다. 따라서 사 용자와 장치 간의 인증과정이 존재하지 않는 태생적 한계가 있 는 블루투스를 고려하여 앱 개발자는 사용자 인증과정을 포함 하는 보안 프로그램을 추가하여 블루투스의 취약성을 보완해 야 한다(Padgette et al., 2017). 이러한 연구자의 제안처럼 보청 기 앱을 실행할 때 사용자 인증과정을 추가하고 사용자와 구입 한 보청기가 서로 일대일 관계에 있음을 증명하는 과정도 추가 되어야 한다. 이를 위해 보청기 제조사는 보청기마다 고유한 코 드번호를 부여하고 사용자는 제공된 코드번호를 인증해야만 앱의 기능을 사용할 수 있도록 하여 블루투스로 연결된 보청 기 앱의 보안 시스템을 향상시켜야 한다.

보청기 착용자는 음향 환경에 따른 주파수 조절이 종종 필요 하다(Keidser, 1996). 특히 거리가 멀어지면 소리 강도가 현저하 게 줄어들기 때문에 청취자는 듣고 싶은 신호로부터 1.8 미터 이 내에 있어야 최적의 음성 명료도를 얻을 수 있다(Kim \& Kim, 2014). 그러므로 소음이 존재하는 환경이나 신호로부터 멀리 떨 어져 있을 경우엔 보청기 볼륨을 증가시켜서 청취에 도움을 받 을 수 있다. 그러나 형태적으로 귀걸이형 보청기나 비교적 중간
정도 크기의 in the ear (ITE)와 in the canal (ITC) 귓속형 보청 기에서는 볼륨을 부착할 수 있지만 completely in canal (CIC) 귓속형 보청기는 크기가 너무 작아서 볼륨을 부착할 수 없으므 로 블루투스 기능이 있는 리모컨을 따로 구입해야만 한다. 더욱 이 블루투스 기능을 작동하면 배터리 소모가 증가되고 중계 장 치인 리모컨이 보청기로부터 1 미터 거리 이내에 있어야 작동하 므로 CIC 귓속형 보청기의 볼륨 컨트롤에 대한 대안으로 스마트 폰에서 생성되는 음향신호로 데이터를 전송하는 방법이 적용되 었다. 이러한 방법으로 크기가 가장 작은 invisible in canal 귓 속형 보청기에서도 볼륨 조절이 가능하며 전력 소모를 줄일 수 있게 되었다. 제조사 E의 경우 697 1,477 Hz 범위의 이중 톤 다중 주파수(dual tone multi frequency) 음향신호를 사용하기 때문에(Ladwa et al., 2009), 앱으로 보청기 볼륨을 조절할 때 생성되는 음향신호를 근처의 다른 사람이 들을 수 있는 단점이 있다. 그러나 제조사 $\mathrm{D}$ 의 경우 이중 톤 다중 주파수 음향신호 보다 더 향상된 기술인 인간의 가청 범위를 넘어서는 15,000 $\mathrm{Hz}$ 주파수 영역의 초음파를 음향신호로 사용하기 때문에 생 성되는 음향신호를 타인이 들을 수 없도록 하였다(Sauer et al., 2014).

이러한 음향신호 기술들은 스마트폰에 앱만 설치하면 보청 기의 볼륨 조절이 가능하여 편리하지만 음향신호가 보청기로 유입만 되면 보청기가 작동하기 때문에 제 3 자가 보청기 착용자 근처에서 앱을 실행할 경우 보청기를 임의로 제어할 수도 있다. 임의적 제어로 보청기를 작동 불능하게 하거나 청력에 피해를 입힐 수 있도록 큰 소리도 입력할 수 있으므로 현재의 음향신 호 방식의 기술에 취약점이 있는 것으로 확인되었다. 음향신호 방식도 앞서 제안한 블루투스 방식에 적용하는 방법처럼 사용 자 인증과정과 사용자와 해당 보청기가 서로 일대일로 인증되 는 과정을 통해서 보청기 고유의 코드번호를 가진 사용자만 앱 을 작동할 수 있도록 하는 방법이 필요하다고 생각한다.

Lee \& Park(2017)의 연구에서는 사물인터넷 기기의 보안성 확보를 위해 사물인터넷 디바이스에 연결된 모든 장치가 소프 트웨어 업데이트를 지원해야 하며 해킹 방지를 위해 검증된 보 안 통신 프로토콜을 사용해야 한다고 하였다. 또한 제도적인 보안성을 확보하기 위해 제품 출시 전 단계에서는 보안상 안전 이 검증된 제품만 출시하도록 하는 강력한 규제가 필요하고 제 품 출시 후에는 자동 소프트웨어 업데이트로 취약점 발생을 신 속히 해결해야 한다고 하였다. 그러나 본 연구에서 밝혔듯이 현 재 보청기 적합 프로그램, 고객 데이터베이스 프로그램, 앱에서 자동 업데이트 기능은 존재하고 있지 않다. 더욱이 매우 빠르 게 변화하고 모든 것이 연결되는 사물인터넷 환경에 청능사나 보청기 착용자는 언제 발생할지 모르는 해킹이나 보안 문제로 부터 자유롭지 못한 것으로 확인되어 자동 업데이트 기능에 도 
움을 받는다면 개인정보 침해의 위협으로부터 좀 더 빠른 대처 가 가능할 것이라 생각한다.

사물인터넷 보청기는 무궁무진한 발전이 기대되지만 현재 제 조사 B에서만 출시되었고 아직 대중화되지는 않았다. 향후 사 물인터넷 보청기는 클라우드 서버를 통해 원격으로 조절이 가 능하고 사용자의 위치를 확인하여 다른 기기와 연결이 가능하 므로 보안의 취약점은 더 증가될 것으로 예상된다. 또한 현재 보청기 제조사에서 개발 및 출시 진행 중인 보청기 원격적합 지 원 시스템은 사물인터넷 기능과는 별도로 클라우드를 통해 앱 과 블루투스로 연결된 보청기를 원격으로 제어할 수 있는 시스 템인데, 기존의 앱과 블루투스의 취약성을 보완한 새로운 알고 리즘이 적용된 시스템을 적용한 후에 보청기 원격적합 지원 서 비스를 사용할 수 있도록 해야 개인정보 유출 사고를 미연에 방지할 수 있을 것이다. 따라서 보청기가 클라우드 서버와 연결 되었을 때를 대비하여 보청기 보안에 관한 연구와 대책이 충분 히 논의되고 진행되어야 할 것으로 생각한다.

결론적으로 보청기 관련 프로그램의 보안에 대하여 조사한 본 연구를 통해 인증과정과 암호화는 사물인터넷 환경에서 가 장 중요한 보안 요소임에도 불구하고 보청기 관련 프로그램은 많은 부분에서 취약점이 발견되었다. 그러므로 현 시점에서 보 청기 적합 프로그램에 사용자 인증과정, 고객 데이터 암호화, 역할기반 접근제어, 감사추적, 자동 업데이트 기능을 적용하여 보안을 강화시킬 필요가 있으며, 보청기 앱에는 사용자 인증과 정과 사용자와 보청기 간의 인증과정을 추가하여 블루투스나 음향신호로 연결된 보청기의 보안을 향상시킬 수 있을 것이라 생각한다. 이는 향후 사물인터넷 보청기 시대를 대비하여 보안 상 문제를 해결하는 데 도움을 줄 것이라 생각한다. 더 나아가 보안은 제조사만의 문제가 아니라 청능사, 보청기 관계자, 일반 사용자들 모두 참여해야 하는 공동의 과제이므로 보청기 제조 사는 보안을 더욱 강화한 제품, 프로그램, 앱 등을 개발해야 할 것이고 보청기 사용자 및 관련된 모든 전문인들은 개인정보 유 출의 심각성을 이해하고 보안에 더욱 관심을 가지고 대처하기 를 기대한다.

중심 단어 : 보안 시스템·개인정보·인증·접근제어·암호화.

\section{Ethical Statement \\ N/A}

\section{Acknowledgments \\ N/A}

\section{Declaration of Conflicting Interests}

There are no conflict of interests.

\section{Funding}

N/A

\section{Author Contributions}

All authors contributed equally to this work. D.K. designed and performed experiments, analyzed data, and wrote the paper; D.K. and T.K. designed and performed experiments in the clinic; D.K. and J.K. provided statistical analysis and critical revision; D.K. designed experiments, analyzed data, and wrote the paper. Also, the authors discussed the results together and implications and commented on the manuscript at each stage.

\section{ORCID iDs}

Dokyun Kim

https://orcid.org/0000-0003-3444-5246

Jinsook Kim

\section{REFERENCES}

Armour, Q. \& Thizy, D. (2010). Developing Successful Healthcare Software: 10 Critical Lessons. Macadamian. Retrieved from http://info.macadamian.com/rs/macadamian/images/Mac_10_Healthcare_Lessons.pdf.

Boadu, E. O. \& Armah, G. K. (2014). Role-based access control (Rbac) based in hospital management. International Refereed Journal of Engineering and Science, 3(9), 53-67.

Chaudhry, J. A., Chaudhry, S. A., \& Rittenhouse, R. G. (2016). Phishing attacks and defenses. International Journal of Security and Its Applications, 10(1), 247-256.

Choi, S. H. (2018). Analysis of Voice Phishing and Cannon Bank Accounts in 2017. Phishing Keeper. Retrieved from http://phishing-keeper.fss. or.kr./fss/vstop/bbs/view.jsp?url=/fss/vstop/1353319504998\&bbsid=13 53319504998\&idx=1522972150586\&num $=242$.

De Capitani di Vimercati, S., Paraboschi, S., \& Samarati, P. (2002). Access control: Principles and solutions. Journal of Software: Practice and Experience, 33(5), 397-421.

Doldouras, S. (2017). Hearing aid technology. Global Journal of Otolaryngology, 6(1), 1-8.

Doughty, K. (2016). Smart AT Support for People with Hearing Loss. International Centre for Usable Home Technology. Retrieved from http:// icuhtec.org/wp-content/uploads/2016/05/Article-of-the-Month-September-2016.pdf.

Gemalto. (2017). The Year of Internal Threats and Accidental Data Breaches. Breach Level Index. Retrieved from https://breachlevelindex.com/assets/Breach-Level-Index-Report-2017-Gemalto.pdf.

ISO/IEC JTC 1. (2015). Internet of Things (IoT). International Organization for Standardization. Retrieved from https://www.iso.org/files/live/ sites/isoorg/files/developing_standards/docs/en/internet_of_things_ report-jtcl.pdf.

Johansen, B., Petersen, M. K., Korzepa, M. J., Larsen, J., Pontoppidan, N. H., \& Larsen, J. E. (2018). Personalizing the fitting of hearing aids by learning contextual preferences from internet of things data. Computers, $7(1), 1-21$.

Keidser, G. (1996). Selecting different amplification for different listening conditions. Journal of the American Academy of Audiology, 7(2), 92-104.

Kent, K. \& Souppaya, M. (2006). Guide to Computer Security Log Management (NIST Special Publication 800-92). Gaithersburg, MD: National Institute of Standards and Technology.

Kim, J. S. \& Kim, C. H. (2014). A review of assistive listening device and digital wireless technology for hearing instruments. Korean Journal of Audiology, 18(3), 105-111.

Ladwa, T. M., Ladwa, S. M., Kaarthik, R. S., Dhara, A. R., \& Dalei, N. (2009). Proceedings from ICICI-BME 2009: Control of Remote Domestic System Using DTMF. Bandung, Indonesia: Institut Teknologi Bandung.

Lee, D. \& Park, N. (2017). Institutional improvements for security of IoT devices. Journal of the Korea Institute of Information Security and Cryptology, 27(3), 607-615.

Ministry of Government Legislation. (2017, July 26). Privacy Act. National Law Information Center. Retrieved from http://www.law.go.kr/lsInfoP.do?lsiSeq=195062\&efYd=20171019\#0000. 
Ministry of Health and Welfare. (2018). Number of People with Registered Disabilities. Korean Statistical Information Service. Retrieved from http://kosis.kr/statHtml/statHtml.do?orgId=117\&tblId=DT_11761 N001\&vw_cd=MT_OTITLE\&list_id $=\& s e q N o=\& l a n g \_m o d e=k o \&$ language $=$ kor\&obj_var_id $=\& i t m \_i d=\&$ conn_path $=K 2$.

Padgette, J., Bahr, J., Batra, M., Holtmann, M., Smithbey, R., Chen, L., et al. (2017). Guide to Bluetooth Security (NIST Special Publication 800-121 Revision 2). Gaithersburg, MD: National Institute of Standards and Technology.

Panse, T. \& Panse, P. (2013). A survey on security threats and vulnerability attacks on bluetooth communication. International Journal of Computer Science and Information Technologies, 4(5), 741-746.

Rios, B. \& Butts, J. (2017). Security Evaluation of the Implantable Cardiac Device Ecosystem Architecture and Implementation Interdependencies. WhiteScope. Retrieved from https://a51.nl/sites/default/files/pdf/Pacemaker\%20Ecosystem\%20Evaluation.pdf.
Roshan, R. \& Ray, A. K. (2016). Challenges and risk to implement IOT in smart homes: An Indian perspective. International Journal of Computer Applications, 153(3), 16-19.

Sandhu, R. S., Coyne, E. J., Feinstein, H. L., \& Youman, C. E. (1996). Rolebased access control models. Computer, 29(2), 38-47.

Sauer, G., Dickel, T., \& Lotter, T. (2014). Acoustic Wireless Control-Connecting Smart Phones to Hearing Instruments. Siemens Whitepaper. Retrieved from https://media.sivantos.com/siemens-website/media/2014/11/2014_11_Acoustic-Wireless-Control.pdf.

Scarfone, K., Souppaya, M., \& Sexton, M. (2007). Guide to Storage Encryption Technologies for End User Devices (NIST Special Publication 800111). Gaithersburg, MD: National Institute of Standards and Technology. Stanislav, M. \& Beardsley, T. (2015). Hacking IoT: A Case Study on Baby Monitor Exposures and Vulnerabilities. Rapid7. Retrieved from https:// www.rapid7.com/globalassets/external/docs/Hacking-IoT-A-CaseStudy-on-Baby-Monitor-Exposures-and-Vulnerabilities.pdf. 